Academic Journal of Social Sciences (AJSS)

Vol. 5, Issue 4 (October - December 2021) PP. 398 - 418

\title{
How Leaders' Motivational Language Boost Innovative Work Behavior of Employee in Chinese Service Sectors: The Mediating Role of Psychological Empowerment.
}

\author{
Muhammad Rafique ${ }^{1}$, Muhammad Arshad ${ }^{2}$ and Asrar Ahmed Sabir ${ }^{3, *}$
}

\begin{abstract}
The study drawing on motivational language theory (MLT), examines how leaders boost innovative work behavior (IWB) through motivational languages. The study also used psychological Empowerment as a mediating variable among leader motivational language (LML) and IWB. The data was collected from 291 employees at work services sectors (airlines, hospitals, and shopping malls) in two main phases. The study collected data with six sub-phases from China's services mentioned above sectors. By taking in survey full-time airline employees working in cargo transportation, ground staff, strategic planning, and front desk. The hospital employees respond mainly to technical workers in OPD, laboratory, and nursing staff. In the end, the study gets in the survey from the employee working in shopping malls, stock handling, and sales and planning department. For innovative work behavior, this study collects data from the shift in charge, supervisors, unit head, manager, and career development department from airlines, hospitals, and shopping malls. The study analyzed the data using SMART-PLS-SEM. The findings of the study indicate that there is a positive relationship between LML and IWB. This study also confirmed that psychological Empowerment mediates the relationship. The study found that leaders' communication during training improves employee productivity. The motivational language of leaders reduces the employee's stress level, and they feel free to give feedback and share their ideas with the supervisor at the workplace. The mutual trust among subordinates and leaders brings them together, making an innovative environment to perform at the workplace. The study theoretically contributes and confirms (MLT) as the best tool to motivate subordinates. Practically this study informed the studied sectors how they implement this model to boost employees' innovative work behavior. In the end, the study also discussed limitations with future directions.
\end{abstract}

Keywords: "Leaders' Motivational Language, Innovative Work Behavior, Psychological Empowerment, Motivational Language Theory

\footnotetext{
${ }^{1}$ School of Public Policy and Management, Xian Jiaotong University, Xian, China.

${ }^{2}$ School of Business, Yunnan University of Finance and Economics, Kunming, Yunnan, China.

${ }^{3}$ Department of Economics and Business administration, Division of Management and Administrative Sciences, The University of Education Lahore, Vehari campus.

Corresponding Author: asrar.ahmed@ue.edu.pk
} 


\section{Introduction}

Leaders' ability to use motivational language is indubitably one of the most effective tools in the organization (Lou \& Ling, 2020). Constantly and over time, past research tells us that the quality of leaders' communication has a reflective effect off such serious organizational consequences for instance retention rate, the satisfaction of job, innovation, loyalty, attendance, knowledge sharing, and performance (Usmanova, 2020; Borchgrevink, 2004; Goleman, 1998; Kramer, 2006; Mayfield \& Mayfield, 2007; Robbins, 2005). Previous literature has confirmed the prominence of leaders' motivational language (LML) in practical human resource (HR) administration of an organization was recognized. In addition, theoretical framework of LML was developed to support thoughtful consideration of changing aspects and effectiveness of leadership behavior related to language inside a company (Usmanova et al., 2020).

LML theoretical framework clarifies exactly how leadership language and announcement behavior can positively affect members and their reactions to their employer (Sara, 2021; Madlock, 2013; Mayfield \& Mayfield, 2018; Sullivan, 1988). Leaders' can utilize verbal communication to carry management objectives, vision, encouragement and support, long-term planning, and administrative activities, thereby impacting their organization succeeding a topdown approach (Mayfield \& Mayfield, 2021, 2016, 2018). Leaders' language and announcement abilities establish their management styles, and through inserted motivating aspects in speech communications, they can substantially affect the application of company goals (Brower, et al., 2007; Guo \& Ling, 2020). Innovative work behavior (IWB) inside organization related to actual leadership (Arshad, 2020). The literature describes that leaders' motivational Language (LML), speech, and communication behavior encourage followers (Madlock, 2013; Mayfield et al., 2021 ; Mayfield \& Mayfield, 2018; Sullivan, 1988). It helps employees understand the purpose and recognize their job activities, which helps them acquire emotive backing (Mayfield \& Mayfield, 2018, 2021; Sullivan, 1988). According to Brower et al. (2007), an upturn in the collective knowledge and emotional attachment is that leaders motivate subordinate's performance and conduct towards the task.

The past studies mainly point out the influence of LML on diverse work results, for example, the performance of employees (Mayfield et al., 1998), commitment to the organization (Madlock, 2013), self-efficacy (Arshad et al., 2021; Mayfield et al., 2021), employee decision making (Mayfield et al., 2015) and psychological safety (Mayfield \& Mayfield, 2021). Whereas these involvements offer significant improvements in psychological Empowerment, companies may struggle to implement the system on a larger scale (Mayfield et al., 2008). In contrast, dyadic conduct between leaders and followers evolves primarily due to leader announcement, such as inspiring semantics (Banks, 2014; Brannon, 2011). Without necessitating major organizational changes, leaders can foster psychological Empowerment among their subordinates (Mayfield et al., 2020; Mayfield \& Mayfield 2017). Furthermore, even if a company does not recognize the importance of fine-tuning psychological Empowerment, specific leader can communicate such adjustments in a dyad (Ashauer \& Macan, 2013; Mayfield et al., 2021). Unfortunately, this resource has not yet been properly investigated by academics. Researchers obligate through some 
headway in their understanding of relationship among communication of leaders and psychological safety through recognizing instructions as of leaders that encourage followers to speak up and participate (Liang et al., 2012; Morrison et al., 2015; Weiss et al., 2018). These researches provide a good theoretical foundation for considering the relationship between LML and other major outcomes. However, best of our information, the link amongst LML and IWB has so far to be explored using behavioral outcomes.

Thus, to fill this particular gap, the research constructs and test a theoretical model to add new knowledge related to motivational language theory (MLT). For this purpose, the study links the relationship between LML and IWB. This study also used an essential mediating variable, psychological Empowerment (Gu et al., 2019). Current research also builds the connection between LML and psychological Empowerment rather than IWB. The leader's communication is crucial to influencing the subordinate's behavior, so this study answers this question through employees' innovative work behavior. Besides this, psychological Empowerment acts as a motivation tool that enhancements members' innovative behavior. The motivational language used by leaders builds confidence within the employee, and that confidence clues to a meaningful outcome in task performance. Therefore, in this study, the link is relating it to IWB. The study checks the straight connection of LML with IWB and the indirect relationship through psychological Empowerment.

This study adds theoretically and practically to motivational language theory and the literature on innovative work behavior and psychological Empowerment. This study adds some critical knowledge in the motivational language theory (MLT) and provides guidelines to the sectors where this study is held and other sectors. This study provides some essential outcomes for leaders to use persuasive language for their subordinates to gain fruitful outcomes for the organization. This study also contributes to training and guiding the employee to more Empowerment in the workplace, using language as a motivational tool and taking timely actions through feedback communication.

\section{Theory and Hypotheses}

The literature on leadership has debated the relationship between LML and other vital outcomes. The era on famous of this work is theoretical. Inside this rivulet, spoken language is an instrument for executive control in extraordinary patchiness (Daft \& Wiginton, 1979). By adding, Gronn (1983) presented an informative ethnographic, linguistic inquiry of how an institute head sustained supremacy from side-to-side the deliberate use of dialogue among employees. Motivational linguistics is an essential component of a leader's message. The term "motivational" refers to how a leader's spoken words can motivate employees to improve work attitudes, behavior, and psychological safety (Gu \& Ling, 2019; Van Quaquebeke \& Felps, 2018; Mayfield \& Mayfield, 2021, 2018; Sullivan, 1988), as well as work performance and job satisfaction (Gu \& Ling, 2019; Van Quaquebeke \& Felps, 2018; Mayfield \& Mayfield, 202 1, 2018). The model of work features (Oldham \& Fried, 2016; Hackman \& Oldham, 1976), people-oriented leadership and model of task (Yukl, 2012), theory of goal setting (Locke \& Latham, 1990), and 
sensemaking theory (Locke \& Latham, 1990) are all deep-rooted in theories of motivation (Weick, 1995).

Sullivan suggested 3 categories of leadership communication: "direction-giving language," "passing on information to reduce insecurity elements," "meaning-making language," and "empathetic language." Sullivan (1988) proposed three types of leadership communication exist: "direction-giving language," "passing on information to decrease insecurity elements," "meaning-making language," and "empathetic language." First, direction-giving language imitates leadership desire to communicating a clear and informative message to subordinates who wish to complete their tasks flawlessly (Sullivan, 1988; Mayfield \& Mayfield, 2018). Leaders' motivational communication ensures that a company announces its mission and goal to meet its deadline (Mayfield \& Mayfield, 2018). As a result, the key characteristics of direction-giving language exist that are linked to the task-oriented leadership model (Yukl, 2012) and the goalsetting theory (Locke \& Latham, 1990). Second, via oral communication, leaders' meaningmaking language communicates the appearance of business goals, work values, traditional values, psychological models, and task relevance to employees (Sullivan, 1988; Mayfield \& Mayfield, 2018). Verbal communication denotation redirects the procedure through which leaders affect in what way their subordinates perceive their starring role in the organization and the right connotation of their job to express figurative meaning (Oldham \& Fried, 2016).

The task's importance and result indicate an active work intention characteristic that initiatives staff to accomplish top-notch job performance (Oldham \& Fried, 2016). Meaningmaking language benefits employees to get an enhanced sense of sincerity as well as commitment from their leaders' verbal messages. The concept of work appearances (Hackman \& Oldham, 1976; Oldham \& Fried, 2016) and sensemaking theory motivate this verbal communication (Weick, 1995). Lastly, sympathetic linguistic aims to launch emotive relationships among subordinates and leadership over communicative competence, with leaders using linguistics to provision and backing subordinates in a variety of work circumstances (Mayfield et al., 1995; Mayfield \& Mayfield, 2018; Morgeson et al., 2004). Without emotional connections, followers believe their administrations show them fever care and distress, and they are less willing to use their creativity to work hard. Employees' well-being and effective conduct will benefit from approaches in which leaders collaborate with them (Schraub et al., 2014). The motivational features of sympathetic language outcome as of positive psychological theory, emotional intelligence theory, and the people-oriented leadership model (Mayfield \& Mayfield, 2018; Yukl, 2012; Dutton et al., 2014).

\subsection{Motivational languages theory (MLT)}

According to MLT, leaders' communication with subordinates can motivate employees by using direction-giving, sympathetic, and meaning-making language. Leaders openly address their staff, motivate them, and support them in improving task performance by utilizing motivational language (Mayfield \& Mayfield, 2020, 2010). Previous research on motivational languages has demonstrated that adopting motivational language in the workplace positively impacts job satisfaction, psychological safety, and organizational outcomes (Mayfield \& Mayfield, 2021, 2010). Sullivan (1988) proposed, direction giving, meaning-making, and sympathetic 
languages, as three dimensions of visible factors, might be recycled to optimally engage core motivating language factors (Sullivan, 1988).

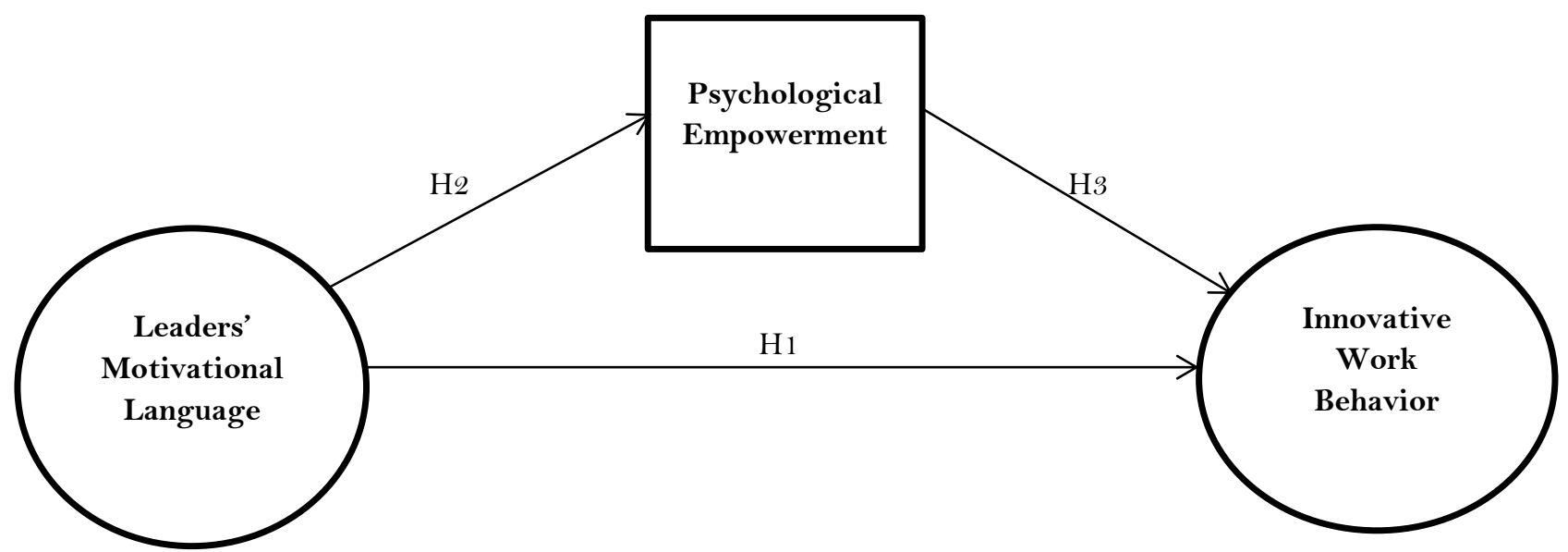

Figure 1: Theoretical Model

\subsection{Leader's Motivational Language and Employee Innovative Work Behavior}

Leaders' communication is the basic behavior that strongly influences the subordinates at the workplace because the words leaders use for their workers directly affect performance (Xue et al., 2020). According to Sullivan (1988). When leaders' language reduced worker role and task doubt, job satisfaction and performance would increase. This type of communication relates to the building aspect of the path-goal theories (Yukl, 1989). The motivational leadership language is a vital communication approach for subordinate's motivation in practical work (Khan et al., 2020). The vital part of leaders' communication is through motivational language; by using motivational language indirectly leaders cultivate a high level of motivation in subordinates towards their job attitudes that effectively improve the job performance (Mayfield et al., 2021 ; Van Quaquebeke \& Felps, 2018; Mayfield \& Mayfield, 2018; Sullivan, 1988;). Goal-setting theory (Locke \& Latham, 1990), sensemaking theory (Weick, 1995), model of work characteristics (Oldham \& Fried, 2016), the model task, and the theory of goal setting all benefit from LML (Yukl, 2012). The leaders' language reflects their intent to close the communication gap and deliver primary and plain information to subordinates who wish to do their tasks efficiently (Ma et al., 2018; Sullivan, 1988). Leaders' motivational language noticeably states the vision and mission and helps set the organization's targets to get timely and potential feedback performance (Mayfield \& Mayfield, 2017). According to Mayfield et al. (1995), the motivation language of leaders is intensely associated with worker satisfaction and performance with all scale validity and reliability. Another research work conceded by Mayfield et al. (1995) confirmed that is expected to maximize performance outcomes up to $7 \%$ when leaders use $10 \%$ more motivational language in the workplace. In addition, motivational language theory (MLT) predicts that the use of motivational language by leadership can directly influence employee job satisfaction, innovation, and performance (Mayfield et al., 1995; Mayfield \& Mayfield, 2009). According to 
(Cristina et al., 2018) the affiliation concerning leaders' motivational language and innovative work behavior. Most of the time, the leaders discuss the business goals and set targets with employees, leading to increased motivation and innovative work. The leaders and their communication play as facilitators to promote emotional commitment and maximize innovation among the university teachers and academics (Sara et al., 2021). Therefore, the motivational words that leaders use for subordinates have the power to encourage and motivate them to work in innovative ways (Mayfield \& Mayfield, 2021). Therefore, we expect that the leaders' motivational language will also affect the IWB in employees of the services sector in China. We hypothesized that:

\section{H1: Leaders' motivational languages (LML) will positively influence innovative work behavior.}

\subsection{Motivational Language and Psychological Empowerment}

Previous studies have shown that leaders' motivational language (LML) positively and significantly impacts the subordinate's attitudes and working manners including, absenteeism, job satisfaction, effective decision making, performance, psychological Empowerment, and psychological safety (Holmes \& Wolff, 2012; Mayfield et al., 2021; Mayfield \& Mayfield, 2018). Furthermore, some studies have shown that ML is generalizable across many scholars' matching outcomes in various circumstances (Madlock \& Sexton, 2015; Mayfield \& Mayfield, 2018). The direction-giving language is used by leaders to inform employees through facts about the actions they must take to achieve their goals, to dispel doubt, and to clarify reward situations (Mayfield et al., 2021; Gutierrez-Wirsching et al., 2015; Mayfield \& Mayfield, 2010). Setting goals in addition to receiving good performance feedback are two instances of this type of communication. Empathetic language, the second element, maintains and initiates supportive emotional relationships between a leader and a subordinate (Mayfield et al., 2021). When a leader applauds a worker's accomplishments or defends their decisions, they employ empathic language. The third factor, meaning-making language, aligns an employee's aspirations inside the organization's vision, recognizes a subordinate's inimitable offerings towards work tasks, and improves awareness of the culture of an organization (Mayfield \& Mayfield, 2006; Mayfield \& Mayfield, 2009; Mayfield et al., 2020).

Motivational language has positively impacted several areas related to staff working environment (Mayfield \& Mayfield, 2004, 2009, 2010; Ma et al., 2018). Several studies have found a link between motivating language and follower work contentment, a term connected to but separate as of psychological Empowerment and psychological safety (Mayfield \& Mayfield, 2020; Ma et al., 2018). These findings imply that motivational language impacts psychological states closely comparable to the motivational language theory (Mayfield et al., 1998). Correspondingly, previous studies found that motivational language takes favorable associations through satisfaction of supervisor, creative support, and intrinsic motivation, entirely by good work setting qualities that must improve a worker's sense of safety and psychological Empowerment (Mayfield \& Mayfield, 2016; Mayfield et al., 2020). Other workplace components connected to psychological Empowerment in studies have also been positively linked to motivational language 
(Mayfield \& Mayfield, 2009; Mayfield \& Levine, 2010). According to the above discussion, we hypothesized that:

\section{H2: Leaders' motivational language positively influences the employee psychological empowerment}

\subsection{Motivational Language, Psychological Empowerment, and Innovative Work Behavior.}

The leaders' can influence the innovative behavior of subordinates to try their best to achieve goals (Majumdar \& Ray, 2011). Leaders' positive attitude maximizes innovation (Kelley \& Borozdina, 2019). Khan and Khan (2019) studied leaders' motivational language to help employee learning behavior. Leaders inspire and encourage subordinates' capability to learn new ways of doing work that maximizes innovative work behavior (Afsar et al., 2014). Therefore, the oral words used by leaders' have the affinity to inspire and motivate their employees to participate in profitable and desired ways (Mayfield et al., 2021).

The leaders' motivational language is positively associated with the members' psychological safety, behavior, feedback performance, satisfaction, and innovation (Gallitto et al., 202 1; Igbaria \& Guimaraes, 1999). From the last decade, the perception of Empowerment takes enlarged attractiveness in management sciences (Menon, 2001; Patterson et al., 2004; Sabir, 2021 ; Spreitzer et al., 1997). Empowerment concentrated on administration practices intended to "empower" workers, like delegating decision-making power. Through Empowerment, the organization's leadership allows employees to watch several responsibilities and roles to enjoy their work independence (Asrar et al, 2018; Paré \& Tremblay, 2007). According to Thomas and Velthouse (1990), when leaders directly communicate with workers, that leads to inspiring them directly, their psychological Empowerment and sense of responsibility also increase. Psychological Empowerment reveals autonomy that leads to self-determination and safety, which further proceeds in continued effort in the work process. Workers can choose a method and make decisions about their tasks (Spreitzer, 1995; Wang et al., 2021). Past studies about leaders' attitudes and styles confirmed that leaders' positive behavior builds such an environment in an organization that helps support subordinates and encourages innovative behavior (Çakar \& Ertürk, 2010; Rani \& Khan, 2017). Additionally, the necessary consequences of psychological Empowerment, like mutual trust, increased among leaders and employees, and this alliance is influential for both parties' innovation performance (Ahmad et al., 2015; Brunetto \& FarrWharton, 2007). As Spreitzer et al. (1997), workers through an advanced level of psychological Empowerment are more practical and influence their working environment. This kind of Empowerment positively influenced innovation. These kinds of control take an individual in the sense of responsibility, lead towards innovative behavior (Knight-Turvey, 2006). A study by Annida and Haranti (2019) confirmed that IWB is the affirmative effect in the 21 st century where employees thick out of the box and keep an eye on innovation. Hence in these concerns, the leaders' play a critical role; the motivational language may raise the innovative behavior reinforced by the theory of motivational language, initially proposed by (Sullivan, 1988).

The mediating variable in this study is psychological Empowerment, and it is the beginning point for driving innovative work behavior. Research has consistently exposed the link between 
job satisfaction and psychological Empowerment (Fong \& Snape, 2015; Castro et al., 2008; Dewettinck \& Van Ameijde, 2011;). It indicates that the more empowered workforces are more gratified than they were (Menon, 2001; Stewart et al., 2010). Furthermore, every element of psychological empowerment grows associated with job satisfaction (Sabir \& Bhutta, 2018; Spreitzer et al., 1997). Too elegant, psychologically empowered workers experience fulfillment in numerous methods (Amundsen \& Martinsen, 2015). Therefore, towards maximizing innovative work behavior or innovation in the firm, the employee may have (i) their willingness to be innovative and (ii) environment for innovative work. Employees need to be psychologically empowered and motivated by leaders (Pieterse et al., 2010). Hence, consistent with the above discussion, the following hypotheses are proposed.

\section{H3: Psychological Empowerment positively relates to innovative work behavior}

H4: Psychological Empowerment intervenes in the association between motivational language and $I W B$.

\section{Method}

\subsection{Data Collection}

For collection of data in this study, we select three types of organizations working in Kunming Yunnan, China (airlines, hospitals, and shopping malls) for the current research survey, because we want to cross-check the effect of leaders' motivational language in different service organizations. The study selected some Chinese airlines such as (China eastern airline, Kunming Airlines, and China Southern Airlines). The second sector of the study used for data collection purposes is the health sector (Calmette hospital and Kunming second people hospital). The third sector of this investigating study used is employees from shopping malls (Wal-Mart, Metro, and Carrefour). The current study contacted the HR and concern department of the targeted organizations and got permission to collect data only for research purposes. At the same time, they confirm the researcher's identity from the concerned university. The researcher briefly introduced the data collection purpose via head-on meetings with the concerned person of the targeted organization. They were also ensuring from us about confidentially of both response and respondents. The researcher requested the entire respondent to read the questions deeply and respond accordingly.

The data collection process consists of two main phases subdivided into six phases. In the first stage of the study, we collect facts from airlines, hospitals, and shopping malls, asking about their point of view about leaders' motivational language and their psychological Empowerment, subdivided first phase (airline phase, hospital phase, and shopping mall phase). After this data collection from the leaders'/supervisors in the second phase, this study also divided the second phase into three sub-phases (airlines, hospitals, and shopping malls).

The current survey gets responses from full-time airline employees working in cargo transportation, ground staff, strategic planning, and front desk. The hospital employees respond mainly to collect data from technical workers in OPD, laboratory, and nursing staff. At last, the study gets in the survey from the employee working in shopping malls, stock handling, and sales 
and planning department. This study collects data from the shift in charge, supervisors, unit head, manager, and career development department from airlines, hospitals, and shopping malls for innovative work behavior. In the first phase of the survey, we collect data in eight weeks in August and September 2021 . And for the second phase, the study collected data in three weeks in October 2021.

The study collects data using convenience sampling from employees and their respective leaders'. By distributing only 500 questionnaires (because of restriction, pandemic prevention, and control along with time and budget constraints), out of which received back 302, 291 were found fully complete and useable for other processes with a response rate $58.4 \%$. The sex of the respondent taking part in the study are 159 females (54.6\%) and 132 males (45.3\%). We collect data from airlines employees about 24.1\%, hospitals employees 33.7\%, and shopping malls employees $42.2 \%$. The age of respondents between 31 to 40 years is almost (44\%). And about $55.3 \%$ of the respondent have bachelor-level education. At the last demographic survey, $61 \%$ of the respondents have 6 to 10 years of experience with a similar organization.

Table 1: Descriptive Statistics

\begin{tabular}{cccc}
\hline $\begin{array}{c}\text { Sample } \\
\text { Information's }\end{array}$ & Types & Number of samples & Percentage \\
\hline Gender & Male & 132 & $45.3 \%$ \\
& Female & 159 & $54.7 \%$ \\
Age & 20-30 years age & 92 & $31.6 \%$ \\
& 31-40 years age & 129 & $44.3 \%$ \\
Level of Education & 41 years age and above & 70 & $24.1 \%$ \\
& Basic education/ & & $25.4 \%$ \\
& diploma & 74 & $55.3 \%$ \\
& Bachelor's degree & 161 & $19.3 \%$ \\
Experienced & Technical education & 56 & $23.1 \%$ \\
& Master & 67 & $61.1 \%$ \\
Industry/Sector & Less than five years & 178 & $15.8 \%$ \\
& 6-10 years & 42 & $24.1 \%$ \\
& 11 years and above & 70 & $33.7 \%$ \\
& Airlines & 98 & $42.2 \%$ \\
\hline
\end{tabular}

\subsection{Measures}

The measures of the study variables stayed recognized from the past investigation, having five points Likert scale from "strongly disagree" to "strongly agree." Entirely the scales have initially been in the English language first interpreted the scale into Chinese to understand the respondent better. The study has leaders' motivational language (LML) as the independent variable and employee IWB as a dependent variable. This study also used psychological Empowerment as a mediating variable. 


\subsection{Leaders' Motivational language (LML)}

LML includes the scale of (Sullivan,1988; Mayfield et al., 1998). In total, 9 item scales were used to measure the leaders' motivational Language (LML).

\subsection{Innovative work behavior (IWB)}

IWB for determining innovative work behavior, this study used (De Jong \& Den Hartog, 2010) scale. We used eight items scale to measure IWB keeping in mind the background of the Chinese environment.

\subsection{Psychological Empowerment}

We used 9 items that were previously used by Spreitzer (1995) to measure psychological empowerment.

\subsection{Control Variables.}

At the superior side by side, the control variables observed are age, gender, level of education, the term (number of years in the same organization with the current leaders), and sector. Scholars realize these variables displays of innovative work behavior: (1) male/female: (Ang et al., 2003); (2) age in years: ( $\mathrm{Ng} \&$ Feldman, 2008); (3) level of education (Amabile \& Conti, 1999); (4) number of years in the same organization: (Wang \& Cheng, 2010).

\section{Analytical Procedures}

To check this study proposed theoretical model, the collected data of the study checked on (PLS-SEM) partial least squares structural equation path modeling. Because the PLS-SEM path modeling is one of the best approaches to finding the variance outcome, this study makes the same approaches (Sarstedt et al., 2014). Along with this, PLS-SEM path modeling is the most advanced and commonly used based on variance (Abro et al., 2020). Before running the test, check the reliability, validity, normality, and Common method bias and find the data is clean and valid for different processes (Hair et al., 2017). The study further processes the data into two distinct steps (1) the measurement model assessment, (2) structural model assessment to get results, report, and analysis, that calculated by using PLS-SEM (Sarstedt et al., 2014).

\subsection{Measurement Model}

The valuation of the measurement model comprises reliability calculation of every element used in the study, content validity, consistency of internal items, and discriminant validity (Hair et al., 2012). The study used Cronbach's $\alpha$ to check data reliability. The results show that the value of $\alpha$ in every construct is more than 0.7 , which covers the satisfaction requirement for reliability (Hair et al., 2011). To measure conduct component reliability (CR) towards approving the level of reliability while constructing the CFA measurement model in table 2. The factor loading was for each item is consistent with its construct that is significant and greater than the 0.70 limits. The value of (AVE) average variance extracted and composite reliability (CR) all reach an average point and display acceptable convergent validity that is 0.824-0.866 (Anderson \& Gerbing, 1988). 
Table 2: Measurement Model

\begin{tabular}{|c|c|c|c|c|c|}
\hline Construct & Items & Loadings & $\begin{array}{l}\text { Cronbach's } \\
\text { Alpha }\end{array}$ & CR & AVE \\
\hline \multirow{12}{*}{$\begin{array}{c}\text { Leaders' } \\
\text { Motivational } \\
\text { Language }\end{array}$} & LML1 & 0.83 & \multirow{10}{*}{0.84} & \multirow{10}{*}{0.82} & \multirow{10}{*}{0.76} \\
\hline & LML2 & 0.85 & & & \\
\hline & LML3 & 0.92 & & & \\
\hline & LML4 & 0.89 & & & \\
\hline & LML5 & 0.87 & & & \\
\hline & LML6 & 0.90 & & & \\
\hline & LML7 & 0.89 & & & \\
\hline & LML8 & 0.92 & & & \\
\hline & LML9 & 0.82 & & & \\
\hline & PSY 1 & 0.89 & & & \\
\hline & $\mathrm{PSY}_{2}$ & 0.84 & \multirow{8}{*}{0.89} & \multirow{8}{*}{0.86} & \multirow{8}{*}{0.69} \\
\hline & PSY3 & 0.90 & & & \\
\hline \multirow{6}{*}{$\begin{array}{l}\text { Psychological } \\
\text { Empowerment }\end{array}$} & PSY4 & 0.92 & & & \\
\hline & PSY 5 & 0.87 & & & \\
\hline & PSY6 & 0.91 & & & \\
\hline & PSY7 & 0.93 & & & \\
\hline & PSY8 & 0.95 & & & \\
\hline & PSY9 & 0.85 & & & \\
\hline \multirow{8}{*}{$\begin{array}{c}\text { Innovative Work } \\
\text { Behavior }\end{array}$} & IWB1 & 0.92 & \multirow{8}{*}{0.86} & \multirow{8}{*}{0.84} & \multirow{8}{*}{0.73} \\
\hline & IWB2 & 0.92 & & & \\
\hline & IWB3 & 0.92 & & & \\
\hline & IWB4 & 0.91 & & & \\
\hline & IWB5 & 0.91 & & & \\
\hline & IWB6 & 0.87 & & & \\
\hline & IWB7 & 0.88 & & & \\
\hline & IWB8 & 0.91 & & & \\
\hline
\end{tabular}

Note: AVE represents average variance extracted, and CR indicates composite reliability

Table 3: Discriminant validity Using Fornell-Larcker Criterion

\begin{tabular}{lccc}
\hline \multicolumn{1}{c}{ Construct } & LML & PSY EMP & IWB \\
\hline $\begin{array}{l}\text { Leaders' Motivational } \\
\text { Language }\end{array}$ & $\mathbf{0 . 8 8}$ & - & - \\
$\begin{array}{l}\text { Psychological } \\
\text { Empowerment }\end{array}$ & 0.63 & $\mathbf{0 . 9 0}$ & $\mathbf{0 . 9 0}$ \\
$\begin{array}{l}\text { Innovative Work } \\
\text { Behavior }\end{array}$ & 0.79 & 0.74 & \\
\hline
\end{tabular}

\section{Note: The bold values are discriminant validity}

Table 2 shows that convergent validity is within acceptable limits. Furthermore, it is shown that the square root of AVE is larger than the correlation among all concepts, which is (0.6950.768) (refer to Table 3). As a result, the findings of this investigation meet all of the minor acceptance criteria. 
Table 4: Path Coefficients

\begin{tabular}{cccc}
\hline Path & $\boldsymbol{B}$ & t-value & p-value \\
\hline LML $\rightarrow$ IWB & 0.62 & 10.42 & 0.000 \\
LML $\rightarrow$ PSY EMP & 0.63 & 7.13 & 0.000 \\
PSY EMP $\rightarrow$ IWB & 0.34 & 6.33 & 0.000 \\
\hline
\end{tabular}

Note: The beta values represent as $(\beta)$

\subsection{Structural Model}

The study goes further to the next step after measuring and approving the validity and reliability. For calculation of the structural model, at bootstrapping, the beta value, $t$ value, and $\mathrm{p}$ values are calculated see table 4. The findings show that leaders' motivational language strongly correlates with creative work behavior and employee psychological empowerment, as measured by IWB (=.622, p.01) and PSY-EMP (=.631, p.01; see Table 4 and Figure 2). As a result of the findings, $\mathrm{H}_{1}$ and $\mathrm{H}_{2}$ significantly support the current study. For current study hypothesis 3, the association between psychological Empowerment and IWB $(\beta=.347, \mathrm{p}<.01)$ is also supported; hence the H3 is also approved for this study.

The study used Preacher and Hayes (2008) for H4 mediation; this study used the rule of thumb to detect the mediating factor of psychological Empowerment between the affiliation of LML and IWB.

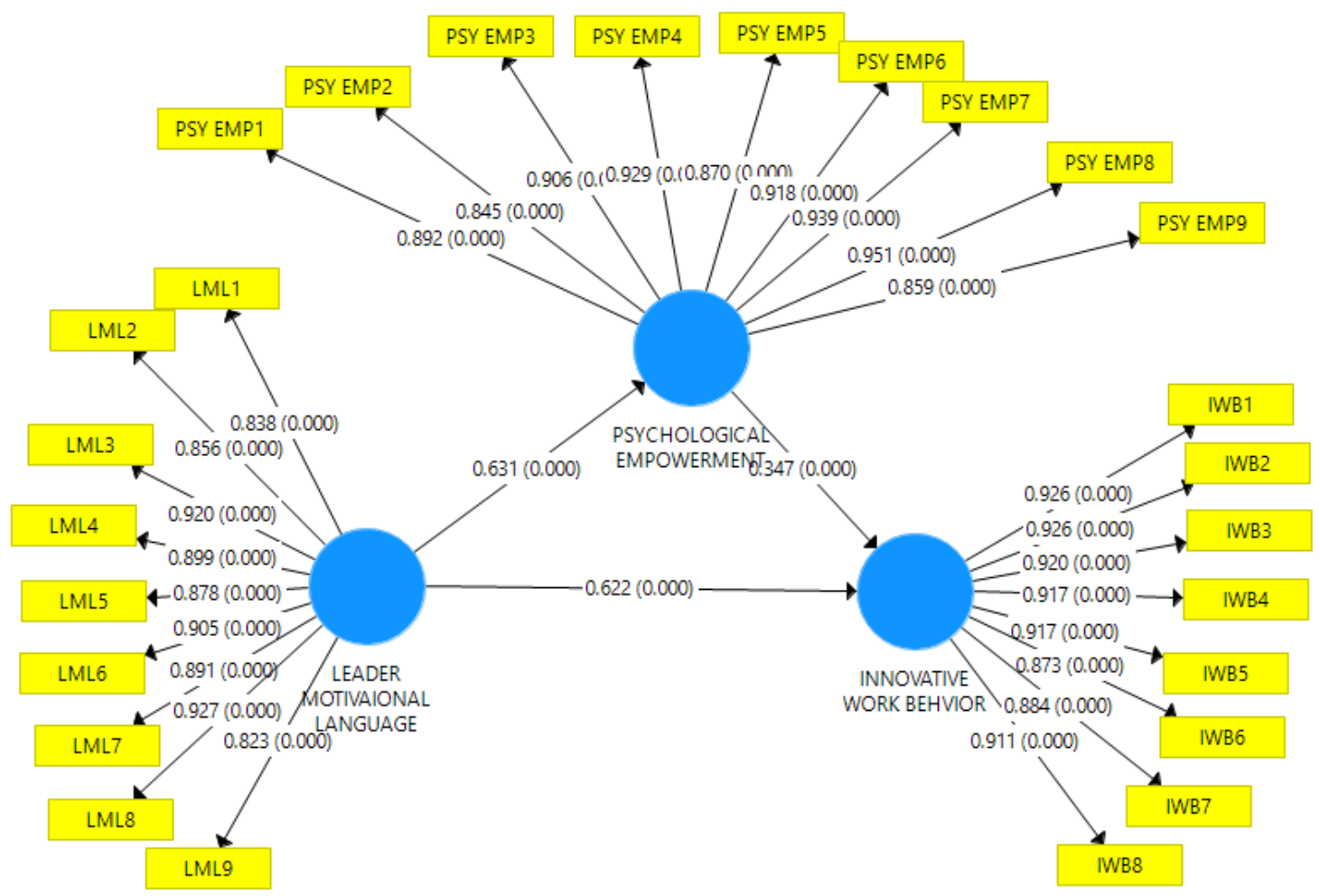

Figure 2: Bootstrapping Indirect Effect 
IWB ( $=.841$, p.01, $\mathrm{t}=5.582)$ was found in the study data while assessing the bootstrapping for particular mediation effects. Furthermore, it is indicated that the indirect effects with 0.147 , 95\% boot confidence interval limit [LL] $=0.031$, and upper limit [UL] $=0.132$ do not have a zero in between. The findings sustenance the mediation hypothesis $\mathrm{H} 4$ in the present investigation. This study also checks the effect of $\mathrm{R}$ square, which is that the one percent change in LML wills leads to change 0.389 in psychological Empowerment (see figure 3)-calculating the total effect in a dependent variable through both independent and mediating variables, the percentage change in both LML and psychological empowering, about 0.780 changes in Innovative work behavior.

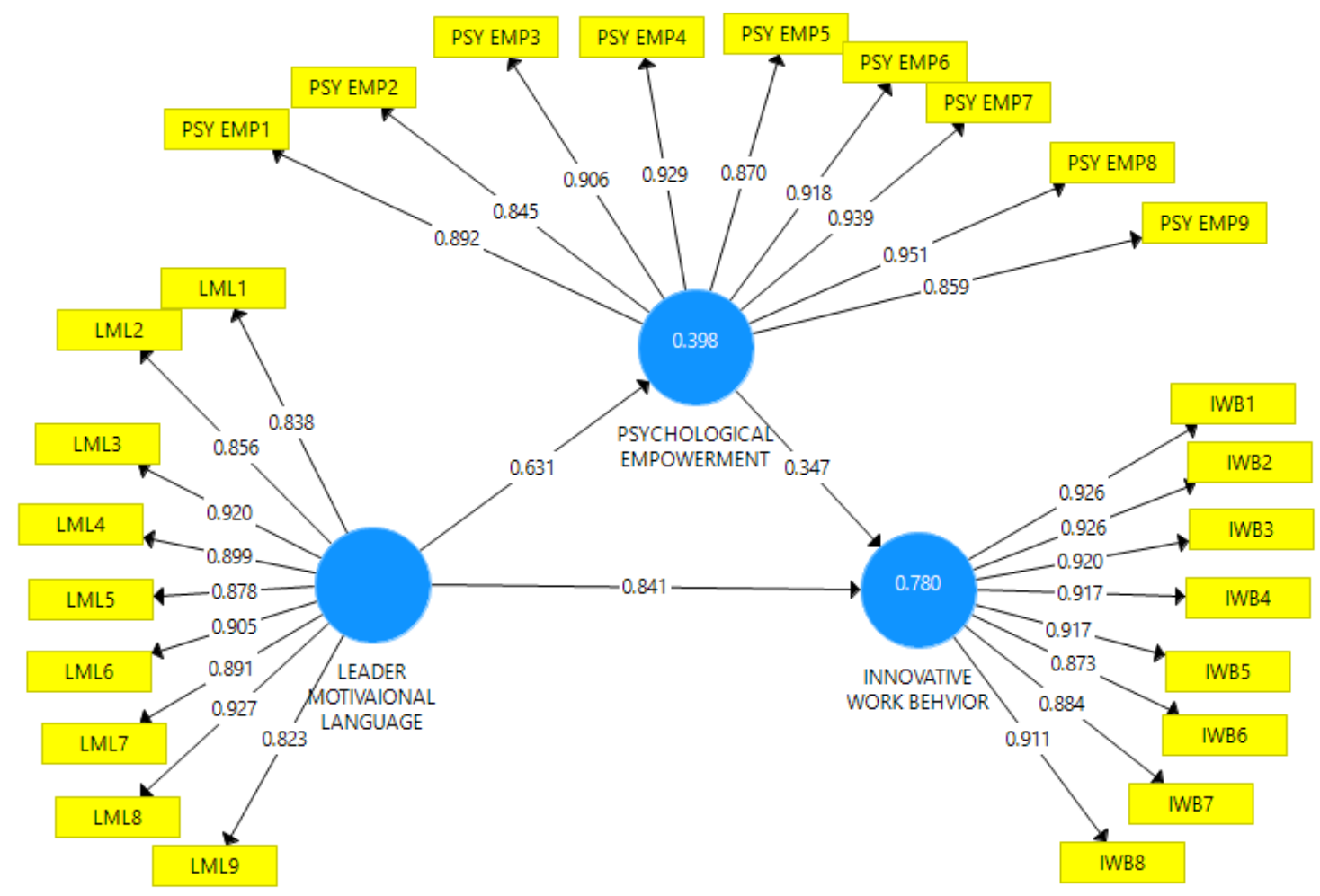

Figure 3: Bootstrapping Total Effect with R Square

\section{Discussion}

This study proves that leaders' motivational language (LML) positively connects with IWB. Similarly, it also confirmed the employee psychological empowerment strengthens the relationship of LML and IWB in the services sector employees in China. The study confirmed that leaders' motivational language boosts innovative behavior among subordinates working in airlines, hospitals, and shopping malls in China. The leaders' motivational languages directly influence the motivation level of subordinates that help them to take responsibility on their shoulders and perform their tasks independently, which encourages employees to finish jobs and responsibilities. That also allows individuals to deal with challenges at work, which leads to 
increased motivation and more inventive work behavior. We increase our information by investigating the contrivance that might upset the relation amongst LML and IWB and enlightening the LML and its impact on IWB. The study findings revealed that psychologically empowered employees liked innovative work rather than everyday tasks because their innovative productivity advanced than others. In calculation, when these workers have good wide-ranging leaders, using motivational language increases innovative work behavior. These findings align with the concept of motivational language theory (Sullivan, 1988). The study finding furthermore confirms a solid association between LML and psychological Empowerment that builds a strong connection among leaders and employees. Leaders' motivational words for subordinates develop mutual trust and feel empowered, bringing positive work behavior changes. The study also confirms the significant and positive connections between employee psychological empowerment and innovative work behavior.

The study findings related to the leaders' motivational communications also linked with the findings (Graen \& Scandura, 1987; Scandura et al., 1986). They found that leaders' communication during training improves employee productivity. The motivational language of leaders reduces the employee's stress level, and they feel free to give feedback and share their ideas with the supervisor at the workplace. The mutual trust among subordinates and leaders brings them together, making an innovative environment to perform at the workplace. According to Mayfield (2016), motivational language is an important tool for leaders to use to control and motivate their staff. According to motivational language theory (MLT), leaders should provide useful information and detailed task instructions. Leaders' language of direction-giving and relationship-building will most likely be employed in day-to-day partnerships with subordinates. Employees feel psychologically empowered due to this reduction in ambiguity; these findings are consistent with motivational language theory (Sarros et al., 2014). Motivational language is an essential implement that leaders use to motivate their subordinates, expect to achieve their task performance, and control their working behavior to be innovative. Thus, the study confirms that the leaders' oral communication (motivational language) leads to higher psychological Empowerment, which further improves the employee's IWB.

\section{Theoretical Contributions}

This study adds to the theoretical literature on psychological Empowerment, innovative work behavior, and leaders' motivational language in various ways. First off, the study adds to the existing knowledge going on IWB. Second, the current study expands on psychological empowerment knowledge and its impact on IWB in a different setting. Third, this study adds to the literature on leaders' motivational language concerning innovative work behavior and psychological Empowerment. Finally, the study adds new information towards the leaders' motivational language theory (MLT), which Sullivan (1988) presented. The leaders' motivational words act as an engine for psychological Empowerment and innovative work behavior. Lastly, the study used psychological Empowerment s mediating variable among LML and IWB, which is fresh and unique to contribute to motivational theory, innovation theory, motivational language theory (MLT), and behavioral theory. 


\section{Practical Implications}

The current study contributes practically to leaders and their subordinates. The results reveal that the employees working in airlines, hospitals, and shopping malls feel stress from their respective supervisors/leaders' while performing their tasks. Leaders' are the person who can play influential roles to motivate and bring innovative work behavior in their subordinates. The study's outcomes will benefit the leaders' working in services sectors (airlines, hospitals, and shopping malls) to show the importance of innovative work behavior through motivational language.

The study outcomes obligate substantial consequences for the motivational language research stream; the motivational language of leaders has noticeably influenced the psychological states of the subordinates and helped improve their working practices. At the same time, the internal satisfaction of the subordinates improves innovative work behavior. And those outcomes will also benefit the organization and management to achieve their goals (Ma et al., 2018; Mayfield et al., 2021; Mayfield et al., 2020). This investigation will encourage scholars to search how motivational language contributes to work environments. This study also provides a direction to the other sectors to check the impact of leaders' motivational language and its implementation. The motivating-language scale can be a powerful and simple technique for assessing a leader's communication abilities. After assessing a leader's language skills, organizations can build appropriate training programs to improve desired outcomes.

\section{Limitations and Future Direction}

While the current study has numerous inspiring findings, it also takes certain limits to mention. Firstly, the study collects data from only three service sector entities from China. Future studies can benefit from collecting data from other sectors and exploring a higher impact of motivational language on innovative work behavior. Secondly, the study used only one mediating factor that is psychological Empowerment. In the future, studies may benefit from some other factors included in the model that directly or indirectly influence innovative work behavior. Finally, the study is taken place in the services sector of China. Future research can test this model in another territory and geographic setting.

\section{Conclusion}

This study provides a vital step towards considering the motivational language of the leaders and its benefits to employees and the organization. The motivational language of leaders, directly and indirectly, influences the workers' behavior. The study focuses on improving workers' innovative work behavior (IWB) by the motivational language used by leaders. Motivational words used by the leaders maximize the trust and remove the stress, leading to increased positive behavior, precisely, the IWB. It also adds that the mediating role of psychological Empowerment delivers an additional provision to the relation of LML and IWB. The study confirmed the indirect influence of leaders' motivational behavior on IWB over psychological Empowerment. Employees feel psychologically empowered when their leaders use motivational words and build 
strong associations amid empolyee and leadership. That improves employees' logic of responsibility, which indirectly boosts innovative work behavior.

Consequently, the harsh words used by leaders badly affect both IWB and the psychological Empowerment of the subordinates. This research can help identify organizational settings that advance the most benefit from ML training and practice. This study hopes that the effects of findings will benefit leaders and practitioners of the services sector in advancing employee innovative work behavior.

\section{References}

Abro, K. A., Siyal, A., Souayeh, B., \& Atangana, A. (2020). Application of statistical method on thermal resistance and conductance during magnetization of fractionalized free convection flow. International Communications in Heat and Mass Transfer, 119, 104971.

Afsar, B., Badir, Y. F., \& Saeed, B. B. (2014). Transformational leadership and innovative work behavior. Industrial Management \& Data Systems, 114(8), 1270-1300.

Ahmad, W., Zaman, N., \& Shah, S. H. (2015). The role of HRM practices on employee's commitment to organization in private sector Banks of Pakistan. A case study of District Abbottabad. International Journal of Research, 2(2), 1288-1304.

Amabile, T. M., \& Conti, R. (1999). Changes in the work environment for creativity during downsizing. Academy of Management Journal, 42(6), 630-640.

Amundsen, S., \& Martinsen, Ø. L. (2015). Linking empowering leadership to job satisfaction, work effort, and creativity: The role of self-leadership and psychological Empowerment. Journal of leadership E organizational Studies, 22(3), 304-323.

Anderson, J. C., \& Gerbing, D. W. (1988). Structural equation modeling in practice: A review and recommended two-step approach. Psychological bulletin, 103(3), 411.

Ang, S., Van Dyne, L., \& Begley, T. M. (2003). The employment relationships of foreign workers versus local employees: A field study of organizational justice, job satisfaction, performance, and OCB. Journal of Organizational Behavior: The International Journal of Industrial, Occupational and Organizational Psychology and Behavior, 24(5), 561-583.

Arshad, M. (2020). the role of leader-member exchange in the relationship of empowering leadership and employee innovative work behavior. International Journal of Business and Management Sciences, 1(2), 44-63.

Arshad, M., Yu, C. K., Qadir, A., Ahmad, W., \& Xie, C. (2021). The moderating role of knowledge sharing and mediating role of employee creative self-efficacy on the association of empowering leadership and employee creativity. International Journal of Management Practice, 14(6), 660-681.

Sabir, A. A., Shahru, A., Isha, N. B., Langove, N., \& Javaid, M. U. (2018). An Integrative Approach to Study Drivers Perceived Stress on Aberrant Driving Behaviour: The Mediation Role of Driver Fatigue. In SHS Web of Conferences EDP Sciences 56, 02-09.

Barroso Castro, C., Villegas Perinan, M. M., \& Casillas Bueno, J. C. (2008). Transformational leadership and followers' attitudes: The mediating role of psychological Empowerment. The International Journal Of Human Resource Management, 19(10), 1842-1863. 
Brower, H. H., Fiol, C. M., \& Emrich, C. G. (2007). The language of leaders. Journal of Leadership Studies, 1(3), 67-80.

Brunetto, Y., \& Farr-Wharton, R. (2007). The moderating role of trust in SME owner/managers' decision-making about collaboration. Journal of Small Business Management, 45(3), 362387.

Çakar, N. D., \& Ertürk, A. (2010). Comparing innovation capability of small and medium-sized enterprises: examining the effects of organizational culture and Empowerment. Journal of Small Business Management, 48(3), 325-359.

Cristina, C., Lucia, P., Sara, S., Francesco, S., Nobile Matteo Alessandro, D., \& Amalia, C. (2018). Study of the efficacy of two extraction techniques from Crithmum maritimum and Salicornia europaea. J. Food Nutr. Res, 6(3), 456-463.

Daft, R. L., \& Wiginton, J. C. (1979). Language and organization. Academy of management Review, $4(2), 179-191$.

De Jong, J., \& Den Hartog, D. (2010). Measuring innovative work behaviour. Creativity and Innovation Management, 19(1), 23-36.

Dewettinck, K., \& Van Ameijde, M. (2011). Linking leadership empowerment behaviour to employee attitudes and behavioural intentions: Testing the mediating role of psychological Empowerment, Creativity and Innovation Management, 40(3), 284-305.

Dutton, J. E., Workman, K. M., \& Hardin, A. E. (2014). Compassion at work. Annu. Rev. Organ. Psychol. Organ. Behav., 1(1), 277-304.

Fong, K. H., \& Snape, E. (2015). Empowering leadership, psychological empowerment and employee Outcomes: Testing a multi-level mediating model. British Journal of Management, 26(1), 126-138.

Gallitto, E., Faggioli, G., Melissano, G., Fargion, A., Isernia, G., Lenti, M., . . Luca, B. (2021). Preoperative and postoperative predictors of clinical outcome of fenestrated and branched endovascular repair for complex abdominal and thoracoabdominal aortic aneurysms in an Italian multicenter registry. Journal of Vascular Surgery, 74(6), 1795-1806. e 1796.

Graen, G. B., \& Scandura, T. A. (1987). Toward a psychology of dyadic organizing. Research in Organizational Behavior, 9, 175-208.

Gronn, P. C. (1983). Talk as the work: The accomplishment of school administration. Administrative Science Quarterly, 14(1) 1-21.

Gu, L., Shi, H., Bian, L., Gu, M., Ling, K., Wang, X., . . Fu, L. (2019). Colour-tunable ultra-long organic phosphorescence of a single-component molecular crystal. Nature Photonics, 13(6), 406-411.

Guo, Y., \& Ling, B. (2020). Effects of leader motivating language on employee task and contextual performance: The mediating role of feedback quality. Psychological Reports, 123(6), 2501-2518.

Gutierrez-Wirsching, S., Mayfield, J., Mayfield, M., \& Wang, W. (2015). Motivating language as a mediator between servant leadership and employee outcomes. Management Research Review, 38 (12), 1234-1250 
Hackman, J. R., \& Oldham, G. R. (1976). Motivation through the design of work: Test of a theory. Organizational Behavior and Human Performance, 16(2), 250-279.

Hair, J. F., Ringle, C. M., \& Sarstedt, M. (2011). PLS-SEM: Indeed a silver bullet. Journal of Marketing Theory and Practice, 19(2), 139-152.

Hair, J. F., Ringle, C. M., \& Sarstedt, M. (2012). Partial least squares: the better approach to structural equation modeling? Long Range Planning, 45(5-6), 312-319.

Hair Jr, J. F., Sarstedt, M., Ringle, C. M., \& Gudergan, S. P. (2017). Advanced issues in partial least squares structural equation modeling: Sage Publications.

Holmes, K. J., \& Wolff, P. (2012). Does categorical perception in the left hemisphere depend on language? Journal of Experimental Psychology: General, 141(3), 439.

Igbaria, M., \& Guimaraes, T. (1999). Exploring differences in employee turnover intentions and its determinants among telecommuters and non-telecommuters. Journal of Management Information Systems, 16(1), 147-164.

Kelley, C. R., \& Borozdina, N. (2019). Internationalizing the US Law School Classroom: Lessons Learned from Teaching Transnationally. The International Lawyer, 52(1), 131-148.

Khan, M. J., Aslam, N., \& Riaz, M. N. (2012). Leadership styles as predictors of innovative work behavior. Pakistan Journal of Social and Clinical Psychology, 9(2), 17-22.

Khan, N. A., \& Khan, A. N. (2019). What followers are saying about transformational leaders fostering employee innovation via organisational learning, knowledge sharing and social media use in public organisations? Government Information Quarterly, 36(4), 101391.

Knight-Turvey, N. (2006). Influencing employee innovation through structural empowerment initiatives: The need to feel empowered. Entrepreneurship Theory and Practice, 43(2), 313324.

Locke, E. A., \& Latham, G. P. (1990). A theory of goal setting E task performance: Prentice-Hall, Inc.

Ma, Q. K., Mayfield, M., \& Mayfield, J. (2018). Keep them on-board! How organizations can develop employee embeddedness to increase employee retention. Development and Learning in Organizations: An International Journal, 32(4), 5-9.

Madlock, P. E. (2013). The influence of motivational language in the technologically mediated realm of telecommuters. Human Resource Management Journal, 23(2), 196-210.

Madlock, P. E., \& Sexton, S. (2015). An application of motivating language theory in Mexican organizations. International Journal of Business Communication, 52(3), 255-272.

Majumdar, B., \& Ray, A. (2011). Transformational leadership and innovative work behaviour. Journal of the Indian Academy of Applied Psychology, 37(1), 140-148.

Mayfield, J., \& Mayfield, M. (2006). The benefits of leader communication on part-time worker outcomes: A comparison between part-time and full-time employees using motivating language. Journal of Business Strategies, 23(2), 131-158.

Mayfield, J., \& Mayfield, M. (2009). The role of leader motivating language in employee absenteeism. The Journal of Business Communication (1973), 46(4), 455-479. 
Mayfield, J., \& Mayfield, M. (2010). Leader-level influence on motivating language: A two-level model investigation on worker performance and job satisfaction. Competitiveness Review: An International Business Journal, 20(5), 407-422.

Mayfield, J., \& Mayfield, M. (2017). Motivating language theory: Effective leader talk in the workplace: Springer.

Mayfield, J., Mayfield, M., \& Kopf, J. (1995). Motivating language: Exploring theory with scale development. The Journal of Business Communication (1973), 32(4), 329-344.

Mayfield, J., Mayfield, M., \& Neck, C. P. (2021). Speaking to the self: How motivating language links with self-leadership. International Journal of Business Communication, 58(1), 31-54.

Mayfield, J., Mayfield, M., \& Sharbrough III, W. C. (2015). Strategic vision and values in top leaders' communications: Motivating language at a higher level. International Journal of Business Communication, 52(1), 97-121.

Mayfield, M., \& Mayfield, J. (2009). The role of leader-follower relationships in leader communication: A test using the LMX and motivating language models. The Journal of Business Inquiry, 8(1), 65-82.

Mayfield, M., \& Mayfield, J. (2016). The effects of leader motivating language use on employee decision making. International Journal of Business Communication, 53(4), 465-484.

Mayfield, M., \& Mayfield, J. (2018). Motivating language and workplace outcomes Motivating Language Theory, Springer 75-94.

Mayfield, M., \& Mayfield, J. (2021). Sound and Safe: The Role of Leader Motivating Language and Follower Self-Leadership in Feelings of Psychological Safety. Administrative Sciences, 11(2), 51-81.

Mayfield, M., Mayfield, J., \& Ma, K. Q. (2020). Innovation matters: creative environment, absenteeism, and job satisfaction. Journal of Organizational Change Management, 33(5), $715-735$.

Mayfield, M. M., \& Levine, J. M. (2010). Opposing effects of competitive exclusion on the phylogenetic structure of communities. Ecology letters, 13(9), 1085-1093.

Menon, S. (2001). Employee empowerment: An integrative psychological approach. Applied Psychology, 50(1), 153-180.

Morgeson, F. P., Delaney-Klinger, K., Mayfield, M. S., Ferrara, P., \& Campion, M. A. (2004). Self-presentation processes in job analysis: a field experiment investigating inflation in abilities, tasks, and competencies. Journal of Applied Psychology, 89(4), 674.

Ng, T. W., \& Feldman, D. C. (2008). The relationship of age to ten dimensions of job performance. Journal of Applied Psychology, 93(2), 392-423.

Oldham, G. R., \& Fried, Y. (2016). Job design research and theory: Past, present and future. Organizational Behavior and Human Decision Processes, 136, 20-35.

Paré, G., \& Tremblay, M. (2007). The influence of high-involvement human resources practices, procedural justice, organizational commitment, and citizenship behaviors on information technology professionals' turnover intentions. Group \& Organization Management, 32(3), 326-357. 
Patterson, M. G., West, M. A., \& Wall, T. D. (2004). Integrated manufacturing, Empowerment, and company performance. Journal of Organizational Behavior: The International Journal of Industrial, Occupational and Organizational Psychology and Behavior, 25(5), 641-665.

Pieterse, A. N., Van Knippenberg, D., Schippers, M., \& Stam, D. (2010). Transformational and transactional leadership and innovative behavior: The moderating role of psychological Empowerment. Journal of Organizational Behavior, 31(4), 609-623.

Rani, T., \& Khan, A. (2017). Financial Variables and Systematic Risk. Chinese Business Review, 16(1), 36-46.

Rowley Mayfield, J., Mayfield, M. R., \& Kopf, J. (1998). The effects of leader motivating language on subordinate performance and satisfaction. Human Resource Management: Published in Cooperation with the School of Business Administration, The University of Michigan and in alliance with the Society of Human Resources Management, 37(3-4), 235-248.

Sabir, S. (2021). A study on Ethical leadership perceptions and its impact on teachers commitment in Pakistan. International Journal of Educational Leadership and Management, 9(1), 28-53.

Sabir, S., \& Bhutta, Z. M. (2018). Leader motivating language as predictor of organizational commitment among generation Y teachers: The mediating role of organizational climate. NUML International Journal of Business E Management, 13(1), 118-133.

Sarros, J. C., Luca, E., Densten, I., \& Santora, J. C. (2014). Leaders and their use of motivating language. Leadership \& Organization Development Journal, 35(3), 226-240.

Sarstedt, M., Ringle, C. M., Henseler, J., \& Hair, J. F. (2014). On the emancipation of PLS-SEM: A commentary on Rigdon (2012). Long Range Planning, 47(3), 154-160.

Scandura, T. A., Graen, G. B., \& Novak, M. A. (1986). When managers decide not to decide autocratically: An investigation of leader-member exchange and decision influence. Journal of Applied Psychology, $71(4), 579$.

Schraub, E. M., Michel, A., Shemla, M., \& Sonntag, K. (2014). The roles of leader emotion management and team conflict for team members' personal initiative: A multilevel perspective. European Journal of Work and Organizational Psychology, 23(2), 263-276.

Spreitzer, G. M. (1995). Psychological Empowerment in the workplace: Dimensions, measurement, and validation. Academy of Management Journal, 38(5), 1442-1465.

Spreitzer, G. M., Kizilos, M. A., \& Nason, S. W. (1997). A dimensional analysis of the relationship between psychological Empowerment and effectiveness satisfaction, and strain. Journal of Management, 23(5), 679-704.

Stewart, J. G., McNulty, R., Griffin, M. T. Q., \& Fitzpatrick, J. J. (2010). Psychological Empowerment and structural Empowerment among nurse practitioners. Journal of the American Academy of Nurse Practitioners, 22(1), 27-34.

Sullivan, J. J. (1988). Three roles of language in motivation theory. Academy of management Review, 13(1), 104-115.

Thomas, K. W., \& Velthouse, B. A. (1990). Cognitive elements of Empowerment: An "interpretive" model of intrinsic task motivation. Academy of Management Review, 15(4), 666-681. 
Usmanova, N., Yang, J., Sumarliah, E., Khan, S. U., \& Khan, S. Z. (2021). Impact of knowledge sharing on job satisfaction and innovative work behavior: the moderating role of motivating language. VINE Journal of Information and Knowledge Management Systems, $51(3), 515-532$.

Van Quaquebeke, N., \& Felps, W. (2018). Respectful inquiry: A motivational account of leading through asking questions and listening. Academy of management Review, 43(1), 5-27.

Wang, A. C., \& Cheng, B. S. (2010). When does benevolent leadership lead to creativity? The moderating role of creative role identity and job autonomy. Journal of Organizational Behavior, $31(1)$, 106-121.

Wang, Y. M., Ahmad, W., Arshad, M., Yin, H. L., Ahmad, B., \& Ali, Z. (2021). Impact of Coordination, Psychological Safety, and Job Security on Employees' Performance: The Moderating Role of Coercive Pressure. Sustainability, 13(6), 3175.

Weick, K. (1995). Sensemaking in organizations,(3) Sage Publications: Inc London.

Xue, Y., Li, X., Liang, H., \& Li, Y. (2020). How does paradoxical leadership affect employees' voice behaviors in workplace? A leader-member exchange perspective. International journal of Environmental Research and Public Health, 17(4), 1162.

Yukl, G. (1989). Managerial leadership: A review of theory and research. Journal of Management, 15(2), $251-289$.

Yukl, G. (2012). Effective leadership behavior: What we know and what questions need more attention. Academy of Management Perspectives, 26(4), 66-85. 